\title{
Propagation Profile and Signal Strength Variation of VHF Signal in Ekiti State Nigeria
}

\author{
I. B. Oluwafemi ${ }^{*}$, O. J. Femi-Jemilohun \\ Department of Electrical and Electronic Engineering, Ekiti State University, Ado Ekiti,Nigeria
}

\begin{abstract}
This paper presents the experimental results of a study on radio frequency attenuation path loss conducted in Ekiti State, Nigeria. The objective of the study is to develop a path loss model comparable to the existing path loss models through a real time application of outdoor VHF signal propagation measurements of the Nigeria Television Authority (NTA) Channel 5 and carrier frequency of $175.25 \mathrm{MHz}$ located in Ado-Ekiti, Ekiti State, Nigeria. Experimental measurements were taken in three routes covering the entire state. Analysis of the data collected from the experiments resulted in models which are in agreement with the existing standard models. Root Mean Square Errors were calculated for all the path loss models. Results show that the signal of the station was generally poor along the routes considered as the deviations of the measured path losses from the free space path loss exceed $6 \mathrm{~dB}$ in most cases.
\end{abstract}

Index Terms: Path loss, signal propagation, attenuation, signal strength

(C) 2017 Published by MECS Publisher. Selection and/or peer review under responsibility of the Research Association of Modern Education and Computer Science

\section{Introduction}

Wireless communication system relies on the propagation of signal waves and data transmission through the free space, hence wireless communication provides mobility for users and satisfies the demand of the subscribers at any location covered by the wireless network [Mardeni R and Kwan K.F, 2010].

Good quality and high capacity networks together with accurate estimation of coverage is extremely important, therefore, accurate design coverage of modern cellular networks and signal strength measurements must be taken into consideration in order to provide an efficient and reliable coverage area.

Several path loss prediction models have been proposed in the literatures but none of these models can be generalized for all environments and localities, instead they are suitable for some specific areas, terrain and climate. Path loss model's parameters can however be adjusted according to the specific environment to obtain

* Corresponding author.

E-mail address: ibto75@gmail.com;dunnifj@yahoo.com 
minimal error between predicted and measured signal strength values [Mardeni R and Kwan K.F, 2010]. The work by Mardeni and Kwan (2010) proposed the optimized Hata path loss empirical model using the least square method for Malaysia while Nadir (2011) investigated seasonal path loss model prediction for Oman. The work by Nadir (2011) calculated the MSE between the measured and the predicted values based on the Okumura-Hata model for the area considered. Similar works were also done by Fagbohun O. O. (2014), Isabona J. \&Konychea C.(2013), Medeisi A \&Kajackas A.(2000), Nadir Z., Elfadhil N \&Touati F.(2008) and Akinbolati et al (2016) with the aims of optimizing the path losses for the investigated cities.

Path loss models are required in network planning, more importantly during the feasibility studies as well as the process of the initial deployment of the network system. They are also used in the prediction of the coverage areas, interference estimation and frequency assignments which are basic elements for network planning process in terrestrial broadcast systems (Nadir 2011). Propagation models can be classified into three types, namely: the empirical models, deterministic models and semi-deterministic models (Oyetunji, S.A,2013)

In this research work, empirical models were employed, Free space, Hata, CCIR and Ericsson path loss models were modified and generalized to suit some routes in Ekiti State of Nigeria, using VHF television signal of Nigeria Television Authority (NTA), Ado Ekiti, channel 5 transmitting at $175.25 \mathrm{MHz}$ frequency band. The research is motivated by the encouragement given by international telecommunication union radio(ITU-R) that scientists and engineers should carry out researches in their localities leading to the development of signal propagation profile in their geographical locations (CCIR Report 239-6,1986).

The organization of this paper is as follows; section II discussed the existing propagation path loss models from literatures as fundamentals to this study. The description of environment where this study was conducted was presented in section III, this was crucial to validate the environment specificity effect on this study. While an adequate explanation on the materials and procedures engaged in achieving the results presented in this study was given in section IV, the results and discussions were presented in section V and section VI concluded on the outcomes and the importance of the research.

\section{Propagation Path Loss Prediction Models}

Quite a number of propagation models exists in literatures and these had been engaged by various researches to analyze the propagation path losses in their different geographical locations. Research being environment specific, and to the best of our knowledge, little or no research have been carried out in this area in the chosen geographical region under consideration in this study. Some of the existing propagation path loss models as reviewed from literature are discussed below.

\section{A. Free Space Propagation Model}

Free Space propagation between transmitting and receiving antennas may be assumed when both antennas are sufficiently high, so that only the direct signal gets to the receiving antenna. The free space model takes only into consideration distance and frequency, hence, it is limited in its ability to accurately predict path loss in most environments (Mardeni and Kwan, 2010, Femi-Jemilohun and Stuart,2014). If the transmitting antenna gain is $G_{t}$ and the transmitting power is $W_{t}$, power density $P_{r}$ at distance $d$ can be expressed as,

$$
P_{r}=\frac{W_{t} G_{t}}{4 \pi d^{2}}
$$

Received Power $W_{r}$ at distance d with a receiving antenna gain $G_{r}$ is therefore 


$$
W_{r}=\frac{W_{t} G_{t}}{4 \pi d^{2}} \times \frac{G_{r}}{4 \pi d^{2}}
$$

Where:

$G_{t}$ is the transmitting antenna gain and $G_{r}$ is the receiving antenna gain, $d$ is distance is speed of propagation $\left(3 \times 10^{8} \mathrm{~m} / \mathrm{s}\right)$ and $\mathrm{f}$ is carrier frequency.

For isotropic transmitting and receiving antennas, $G_{t}=G_{r}=1$ and if distance $d$ is expressed in $\mathrm{km}$ and the carrier frequency $f$ in $\mathrm{MHz}$, the loss between $W_{r}$ and $W_{t}$ in $\mathrm{dB}$ can be expressed as:

$$
L_{f s}=32.45+20 \log _{10} f+20 \log _{10} d
$$

Where $L_{f s}(\mathrm{~dB})$ is free space loss between two isotropic antennas.

\section{B. Okumura Propagation Model}

This is a mathematical model developed by Okumura. It is the most extensively used for signal propagation prediction model in mobile communication and is recognized by the International Telecommunication Union (ITU) (CCIR Report 1145, 2000),

The Okumura model for urban area is a radio propagation model that was built into three modes which are urban, sub -urban, and open areas. This model assumes that the path loss between the transmitter and receiver in the terrestrial propagation environment can be mathematically expressed as:

$$
L=L_{F S L}+A_{F S L}-H_{T U}-H_{R U}-\sum K_{\text {correlation }}
$$

Where $L$ is median path loss between the transmitter and receiver expressed in $\mathrm{dB}, L_{F S L}$; Path loss of the free space in $\mathrm{dB}, A_{F S L}$ : Basic median attenuation, $H_{T U}$ transmitter height gain correction factor in $\mathrm{dB}, H_{R U}$ receiver height gain correction factor in $\mathrm{dB}$ and $K_{\text {correlation }}$ : correction factor gain (such as type of environment, water surfaces, isolated obstacles).

\section{Okumura-Hata Propagation Model}

This model was derived from Okumura field strength curves and various path loss equations for different types of environments predicted. For Hata model, distance from the base station ranges from $1 \mathrm{~km}$ to $20 \mathrm{~km}$, mobile antenna height is between $1 \mathrm{~m}$ and $10 \mathrm{~m}$, base station antenna height is between $30 \mathrm{~m}$ and $200 \mathrm{~m}$ and the carrier frequency is between $150 \mathrm{MHz}$ and $1500 \mathrm{MHz}$, it is classified into urban area, sub-urban area and open space models. Path loss for Hata Model is defined as:

$$
\begin{aligned}
& L_{p}=A+B \log _{10} d(\text { urban Area }) \\
& L_{p}=A+B \log _{10} d-C(\text { Sub-urban Area }) \\
& L_{p}=A+B \log _{10} d-D(\text { Rural- Area })
\end{aligned}
$$


where:

$$
\begin{aligned}
& A=69.55+26.16 \log _{10}\left(f_{c}\right)-13.82 \log _{10}\left(h_{b}\right)-a\left(h_{m}\right) \\
& B=44.9-6.55 \log _{10}\left(h_{b}\right) \\
& C=5.4+2\left[\log _{10}\left(\frac{f c}{28}\right)\right]^{2}-19.33 \log _{10}\left(f_{c}\right) \\
& D=4.78\left[\log _{10}(f)\right]^{2}-18.33 \log 10(f)+40.94
\end{aligned}
$$

The parameter $a\left(h_{m}\right)$ is a "correction factor"

For medium or small city:

$$
a\left(h_{m}\right)=\left[1.1 \log 10 f_{c}-0.7\right] h_{m}-\left[1.56 \log _{10}(f c)-0.8\right]
$$

For large city:

$$
a\left(h_{m}\right)=\left[8.23 \log _{10} 1.54 h_{m}\right]^{2}-1.1
$$

For

$$
f c \leq 200 \mathrm{MHz}
$$

$$
a\left(h_{m}\right)=3.2 \log _{10}\left(11.75 h_{m}\right]^{2}-4.97
$$

For

$$
f \geq 400 \mathrm{MHz}
$$

Where:

$h_{m}$ is the mobile antenna height above local terrain height $(\mathrm{m}), d$ is the distance between the mobile antenna and the base station, $h_{b}$ the base station antenna height above local terrain height $(\mathrm{m})$ and $f c$ is the carrier frequency $(\mathrm{MHz})$.

\section{CCIR Path Loss Model}

Comité consultatif international pour la radio (CCIR), which in English means Consultative Committee on International Radio was founded in 1927 and over the years merged with the original ITU and several other organisations. In 1992, CCIR now known as International Telecommunication Union Radio Communication Sector (ITU-R) published an empirical formula for combined effects of free space path loss and terrain induced 
path loss given as (CCIR Report 567-3, 2000),

$$
\begin{aligned}
& L_{C C I R}=69.55+26.16 \log _{10}\left(f_{M H z}\right)-13.82 \log _{10}\left(h_{b}\right)-a\left(h_{m}\right)+ \\
& {\left[44.9-6.55 \log _{10} h_{b}\right] \log _{10}\left(d_{k m}\right)-B}
\end{aligned}
$$

Where $h_{b}$ and $h_{m}$ are the base station and mobile antenna heights in metres respectively, $d_{k m}$ is the link distance in kilometres, $f_{M H z}$ is the frequency in megahertz,

$$
\begin{aligned}
& a\left(h_{m}\right)=\left[1.1 \log _{10}\left(f_{M H Z}\right)-0.7\right]-\left[1.56 \log _{10}\left(f_{M H Z}\right)-0.8\right] \\
& B=30-25 \log _{10}(\% \text { of area coveredbybuildings })
\end{aligned}
$$

\section{E. Ericsson Model}

Ericsson Model is a modified Hata model that gives allowance for changing the parameters according to the propagation environment. Path loss according to this model is given as (CCIR Report 567-3, 2000):

$$
\begin{aligned}
& L_{E}=a_{0}+a_{1} \log _{10}(d)+a_{2} \log _{10}\left(h_{b}\right)+a_{3} \log _{10}\left(h_{b}\right) \cdot \log _{10}(d)- \\
& 3.2\left[\log _{10}\left(11.75 h_{r}\right)^{2}\right]+g(f)
\end{aligned}
$$

Where $g(f)$ is defined by

$$
g(f)=44.49 \log _{10}(f)-4.78\left(\log _{10}(f)\right)^{2}
$$

and $f$ : frequency $(\mathrm{MHz}), h_{b}$ : transmission antenna height $(\mathrm{m}), h_{r}$ : receiver antenna height $(\mathrm{m})$. The default values of $a_{0}, a_{1}, a_{2}, a_{3}$ are $36.2,30.1,12.0$ and 0.1 respectively for urban terrain.

\section{Study Area}

Ekiti State of Nigeria (Fig. 1) was chosen for this research, it is one of the 36 states in Nigeria, situated in the western part of the country. Ado -Ekiti is the capital of Ekiti State where NTA Channel 5 base station used for the study is situated. The parameters of this broadcasting station are given in Table.1. Three routes were considered, covering the northern and the western part of the state. The effective isotropic radiated power (EIRP) of the transmitter of this television station during the period of this investigation was $3.5 \mathrm{KW}$ and the transmitting antenna was mounted on a mast of height $167.5 \mathrm{~m}$. 


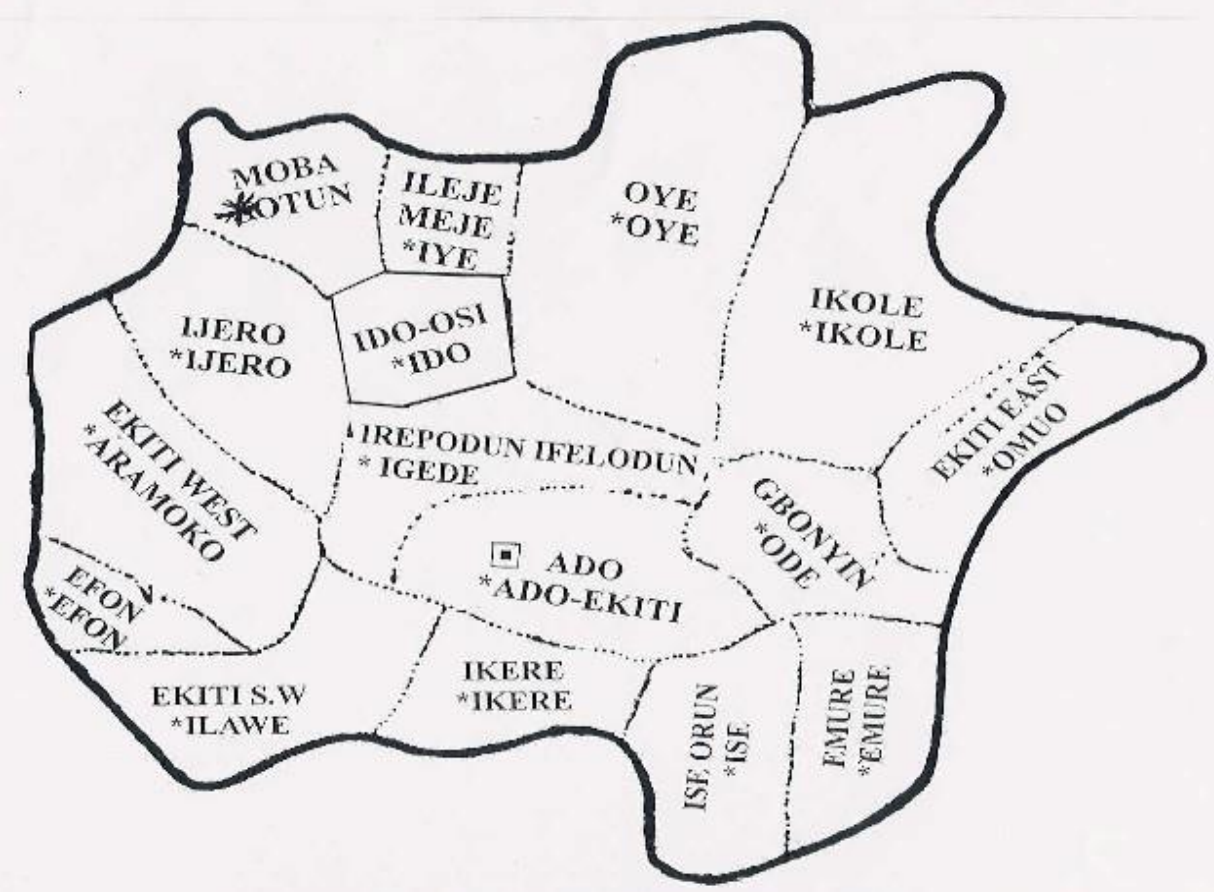

MAP OF EKITI STATE

Fig.1. Map of Ekiti-State (www.earth google /map gallery)

Table 1. Parameters of the N.T.A. Channel 5 Ado-Ekiti Broadcasting Station

\begin{tabular}{ll}
\hline Parameters & Value \\
\hline Frequency of Operation & Very High Frequency \\
Frequency Bandwidth & $175.25 \mathrm{MHz}$ \\
Transmitting Power & $5 \mathrm{KW}$ \\
Effective Isotropically Radiated Power & $3.5 \mathrm{KW}$ \\
Antenna Directivity & Omni-directional \\
Antenna Polarization & Vertical \\
Antenna gain & $12 \mathrm{~dB}$ \\
Maximum height of the transmitting antenna & $167.5 \mathrm{~m}$ \\
\hline
\end{tabular}

\section{Materials and Method}

The Measurements of the electric field strength were taken at selected points along three routes in EkitiState using a Digital signal strength meter, BC1173, 75 ohms input, A/c 100V r.m.s max, DC 9V from DBC Technologies. Measurements were carried out in all the towns and villages in the three routes. The measured field strength values, the location coordinate of each point of measurements, the elevation above sea level and the line of sight distance from the base station were recorded for analysis. 


\section{Results and Discussion}

Tables 2, 3 and 4 show the measurements of signal propagation of NTA along the three routes considered. The tables show the distances from the base stations along the path of measurements, the elevations above sea levels at the point of measurements, the measured signal strength at each point of measurement and the path loss along the routes.

Fig.2, Fig.4, and Fig.6 show the elevations and the propagation path losses along Route A, B and C respectively. It is observed that there is a slight correlation along the routes between the path losses and the elevations. Locations with higher elevations appear to have reduced path losses as compared with locations with lower elevations. Fig.3, Fig.5 and Fig.7 show the propagation path losses along routes A,B and C respectively.

It is observed from the three plots that the path losses along the routes increase with distances from the base stations. This is in accordance with the inverse square law for signal propagation. The plots of the propagation path losses are however observed to be pronouncedly uneven due to irregular elevations of the surfaces of the grounds, the presence of hills, vegetations and atmospheric factors such as refraction, absorption along the routes of measurements.

Table 2. Signal Propagation Data for Route A

\begin{tabular}{|c|c|c|c|c|c|c|c|}
\hline $\mathrm{S} / \mathrm{N}$ & $\begin{array}{l}\text { Distance } \\
(\mathrm{km})\end{array}$ & Elevation $(\mathrm{m})$ & $\begin{array}{l}\text { Field } \\
(\mathrm{dB} \mu \mathrm{V})\end{array}$ & Strength & $\begin{array}{l}\text { Path loss } \\
(\mathrm{dB})\end{array}$ & Location & Town \\
\hline 1. & 0.00 & 516.00 & 79.200 & & 0.000 & Base Station & Ado-Ekiti \\
\hline 2. & 17.00 & 409.10 & 37.980 & & 41.220 & EKSU Campus 1 & Ado-Ekiti \\
\hline 3. & 17.50 & 418.40 & 36.800 & & 42.400 & EKSU Campus 2 & Ado-Ekiti \\
\hline 4. & 19.00 & 432.12 & 32.720 & & 46.480 & Central Mosque & Iworoko-Ekiti \\
\hline 5. & 32.40 & 551.42 & 32.560 & & 46.640 & Ayegbaju-Ekiti & Ayegbaju-Ekiti \\
\hline 6. & 34.10 & 564.12 & 38.440 & & 40.760 & UBA & Oye-Ekiti 1 \\
\hline 7. & 37.80 & 531.52 & 37.900 & & 41.300 & Oye-Ekiti & Oye-Ekiti 2 \\
\hline 8. & 51.60 & 525.05 & 33.800 & & 45.480 & FGC & Ikole-Ekiti \\
\hline 9. & 54.20 & 523.00 & 24.860 & & 54.340 & $\begin{array}{l}\text { St. Patrick catholic } \\
\text { church }\end{array}$ & Oke-Ayedun \\
\hline 10. & 57.10 & 524.16 & 23.740 & & 55.460 & Methodist Church & Odo-Ayedun \\
\hline 11. & 77.10 & 546.00 & 32.020 & & 47.180 & Omuo Comm Gram & Omuo-Ekiti \\
\hline
\end{tabular}

Table 3. Signal Propagation Data for Route B

\begin{tabular}{lllllll}
\hline S/N & $\begin{array}{l}\text { Distance } \\
(\mathrm{km})\end{array}$ & Elevation $(\mathrm{m})$ & $\begin{array}{l}\text { Field Strength } \\
(\mathrm{dB} \mu \mathrm{V})\end{array}$ & Pathloss $(\mathrm{dB})$ & Location & Town \\
\hline $\mathbf{1 .}$ & 0.00 & 516.00 & 79.200 & 0.000 & Base station & Ado-Ekiti \\
$\mathbf{2 .}$ & 17.00 & 409.10 & 37.980 & 41.220 & EKSU Campus 1 & Ado-Ekiti \\
$\mathbf{3 .}$ & 17.50 & 418.40 & 36.800 & 42.400 & EKSU Campus 2 & Ado-Ekiti \\
$\mathbf{4 .}$ & 19.00 & 432.12 & 32.720 & 46.480 & Central Mosque & Iworoko-Ekiti \\
$\mathbf{5 .}$ & 37.80 & 531.52 & 37.900 & 41.300 & Oye-Ekiti 2 & Oye-Ekiti 2 \\
$\mathbf{6 .}$ & 48.00 & 589.30 & 25.540 & 53.660 & Itaji Community & Itaji-Ekiti \\
$\mathbf{7 .}$ & 52.00 & 603.40 & 26.280 & 52.920 & Skye Bank & Ayede-Ekiti \\
$\mathbf{8 .}$ & 57.50 & 574.50 & 21.06 & 57.140 & Central Mosque & Isan-Ekiti \\
\hline
\end{tabular}


Table 4. Signal Propagation Data for Route C

\begin{tabular}{|c|c|c|c|c|c|}
\hline NO. & Elevation & $\begin{array}{l}\text { Distance } \\
(\mathrm{km})\end{array}$ & $\begin{array}{l}\text { Field Strength } \\
(\mathrm{dB} \mu \mathrm{V})\end{array}$ & Path Loss (dB) & Town \\
\hline 1. & 516.00 & 0 & 79.3 & 0.00 & Ado Ekiti \\
\hline 2 & 409.12 & 17 & 37.60 & 41.7 & Ado Ekiti \\
\hline 3. & 418.42 & 17.5 & 37.30 & 42 & Ado Ekiti \\
\hline 4. & 432.12 & 19.0 & 32.6 & 46.7 & Iworoko Ekiti \\
\hline 5. & 574.42 & 25.7 & 30.7 & 48.6 & Ifaki \\
\hline 6. & 588.52 & 34.4 & 30.1 & 49.2 & Ido Osi \\
\hline 7. & 561.52 & 38.1 & 29.3 & 50 & Ido Osi \\
\hline 8. & 564.22 & 39.4 & 29.3 & 50 & Ido Osi \\
\hline 9. & 595.52 & 43.7 & 28.7 & 50.6 & Usi Ekiti \\
\hline 10. & 554.52 & 45.1 & 28.6 & 51.3 & Usi Ekiti \\
\hline 11. & 567.22 & 47.8 & 28.0 & 51.3 & Ayetoro Ekiti \\
\hline 12. & 602.62 & 52.1 & 27.6 & 51.7 & Otun Ekiti \\
\hline 13. & 602.62 & 53.0 & 27.3 & 52 & Otun Ekiti \\
\hline
\end{tabular}

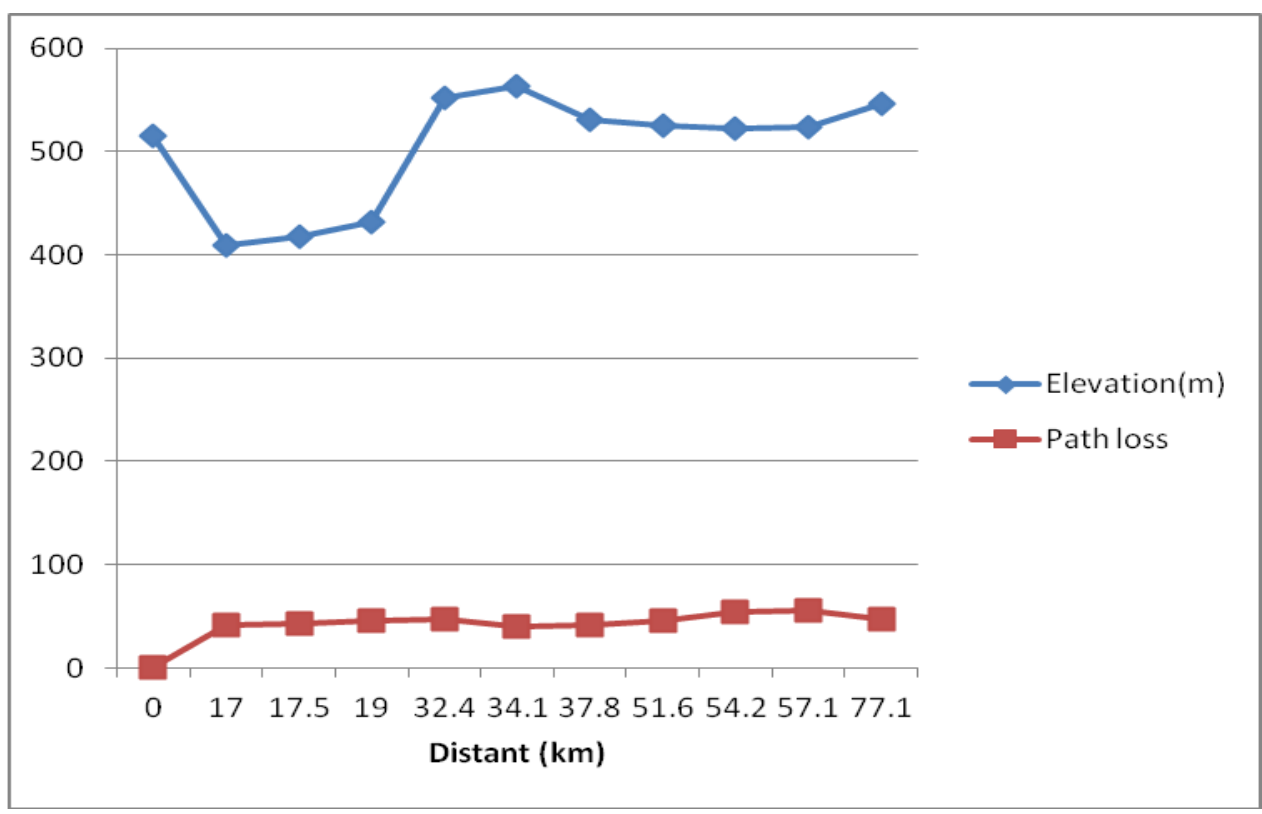

Fig.2. Elevation and propagation path loss for route A 


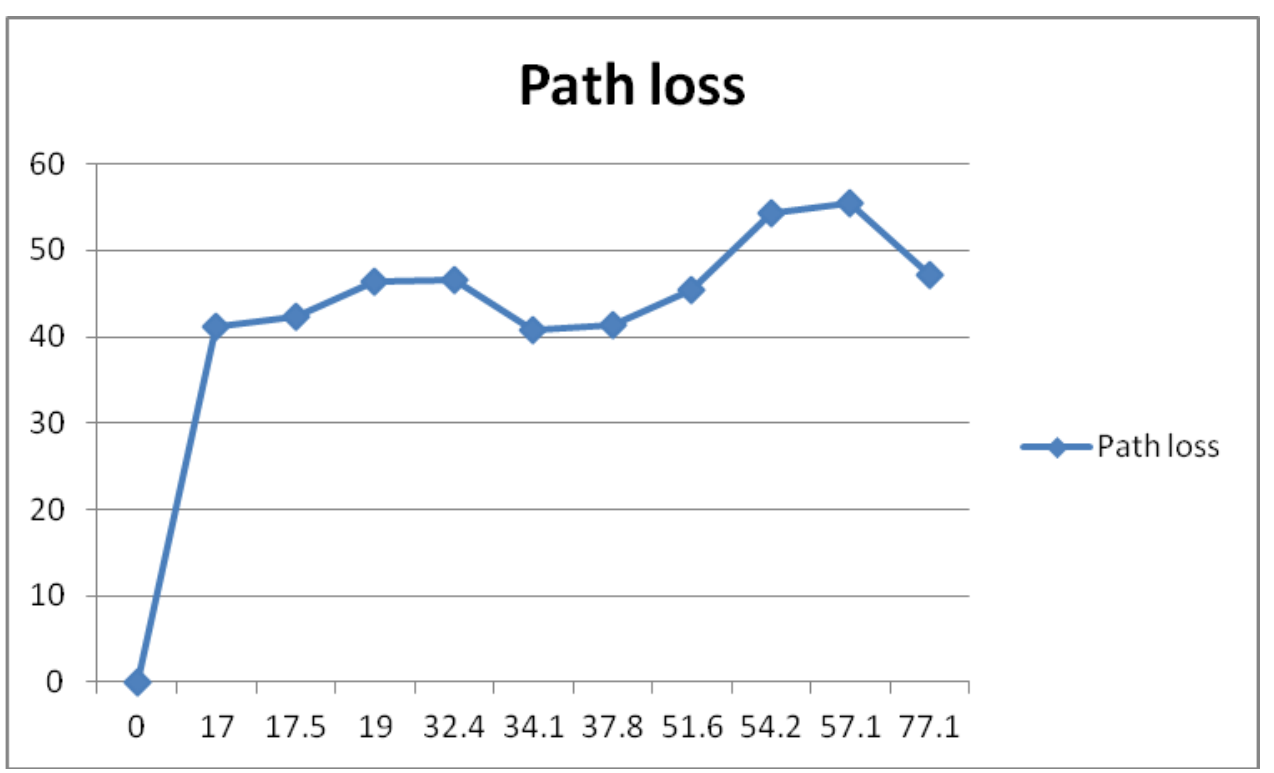

Fig.3. Measured propagation path loss for route A

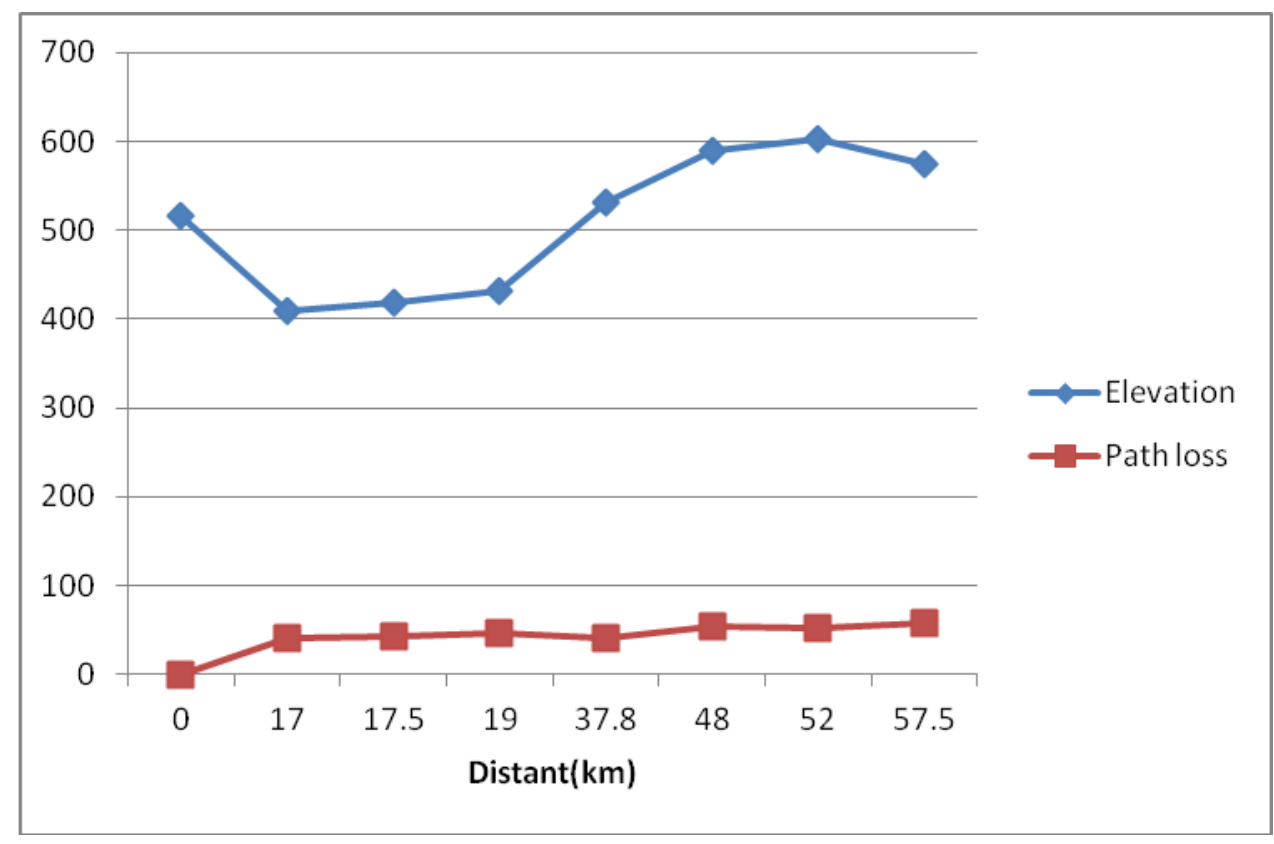

Fig.4. Elevation and propagation path loss for route B 


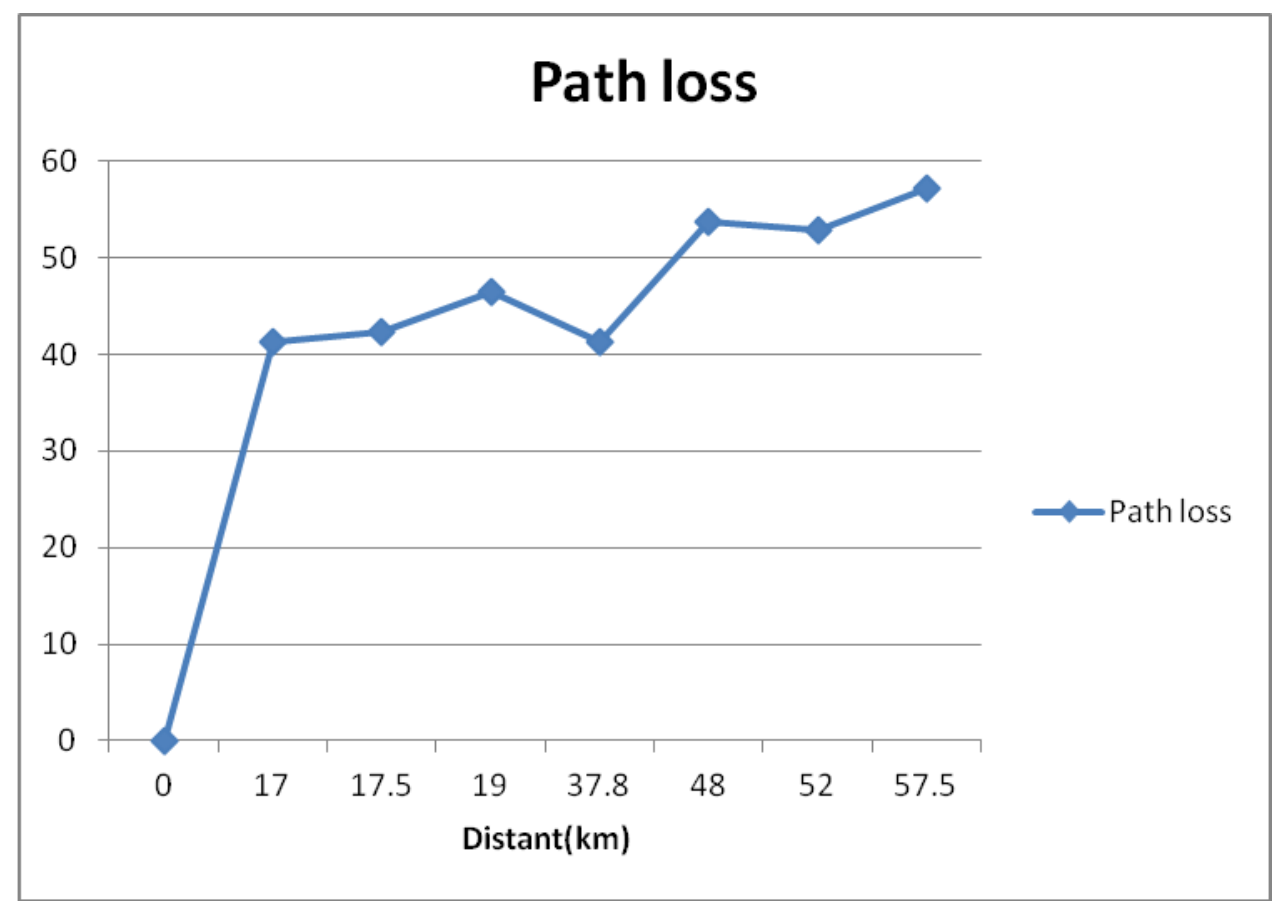

Fig.5. Measured propagation path loss for route B

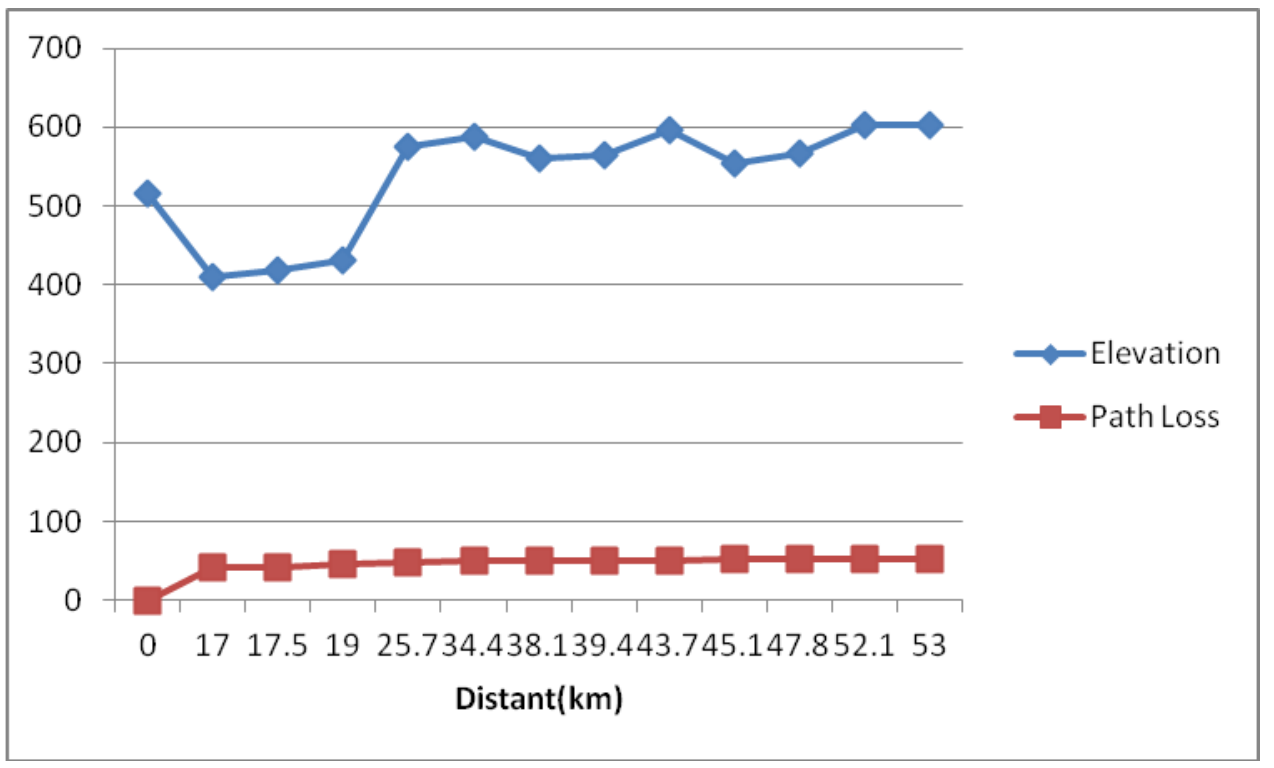

Fig.6. Elevation and propagation path loss for route $\mathrm{C}$ 


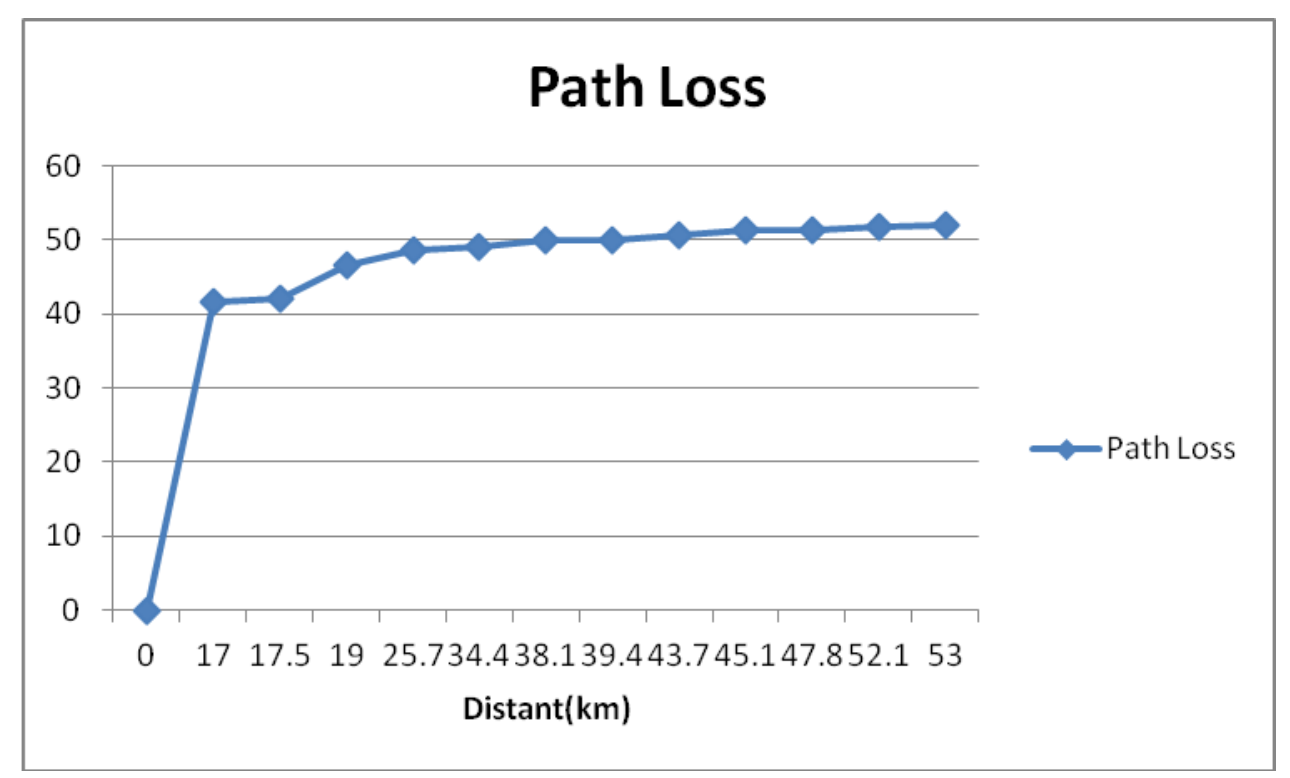

Fig.7. Measured propagation path loss for route $\mathrm{C}$

Tables 5, 6 and 7 show the results of the calculated path losses using the existing models. While Fig. 8, 9 and 10 show the plots of the measured path losses along route $\mathrm{A}, \mathrm{B}$ and $\mathrm{C}$ respectively against the existing empirical models. It can be observed from the plots that measured path losses are uneven as compared with those of the empirical models because of the presence of hills and mountains along the routes. In table 8, the least root mean square errors were computed for the three routes. It is observed from the table that the Hata (sub-urban) has the least root mean square errors for routes $\mathrm{A}, \mathrm{B}$ and $\mathrm{C}$ while the free space model has the highest least mean square errors for the three routes as expected. It can therefore be concluded that the Hata (sub Urban) is the closest among path loss models considered to predict the signal path loss for the VHF signals in all the routes covered in this study.

In Fig. 8, a deviation of the measured path loss from the free space path loss of $6 \mathrm{~dB}$ is noticeable for route A except at Oke Ayedun and Odo Ayedun where the deviation is more that $6 \mathrm{~dB}$. This could be attributed to a low elevation between these two towns, hence weak signal reception. In Route B, the deviation of the measured path loss from the free space path loss is greater than $6 \mathrm{~dB}$ at a distance greater than $48 \mathrm{~km}$ from the base station as revealed in Fig.9. At this distance the signal was very weak hence reception became very poor. While in route $\mathrm{C}$, the deviation of the measured path loss from the free space path loss is greater than $6 \mathrm{~dB}$ at a distance of greater than $25 \mathrm{~km}$ from the base station as depicted in Fig.10. The distance at which the deviation exceeds $6 \mathrm{~dB}$ was shorter in comparison with other routes because of the elevation of this route being highly hilly; therefore, the signal strength along this route was generally poor. 
Table 5. Result of the Path Loss obtained using Ericsson, Hata-Suburban, Hata-Open, Free Space, and CCIR Path Loss Prediction Model for Route A

\begin{tabular}{|c|c|c|c|c|c|c|c|c|}
\hline $\mathrm{S} / \mathrm{N}$ & $\begin{array}{l}\text { Distant } \\
(\mathrm{Km})\end{array}$ & Measured(dB) & $\begin{array}{l}\text { Ericsson } \\
\text { Model } \\
(\mathrm{dB})\end{array}$ & $\begin{array}{l}\text { Hata- } \\
\text { Sururban } \\
\text { Model } \\
\text { (dB) }\end{array}$ & $\begin{array}{l}\text { Hata-Open } \\
\text { Model } \\
(\mathrm{dB})\end{array}$ & $\begin{array}{l}\text { Free Space } \\
\text { Model (dB) }\end{array}$ & $\begin{array}{l}\text { CCIR Model } \\
\text { (dB) }\end{array}$ & Town \\
\hline 1. & 0.00 & 0.000 & 0 & 0 & 0 & 0 & 0 & Ado-Ekiti \\
\hline 2. & 17.00 & 41.220 & 44.60401 & 44.40248 & 40.45927 & 40.16622 & 39.02251 & Ado-Ekiti \\
\hline 3. & 17.50 & 42.400 & 44.61432 & 44.43867 & 40.51618 & 40.18765 & 38.78299 & Ado-Ekiti \\
\hline 4. & 19.00 & 46.480 & 44.65544 & 44.51901 & 40.64204 & 40.24816 & 39.46451 & $\begin{array}{l}\text { Iworoko- } \\
\text { Ekiti }\end{array}$ \\
\hline 5. & 32.40 & 46.640 & 44.83947 & 45.18419 & 41.66022 & 40.63092 & 40.16058 & $\begin{array}{l}\text { Ayegbaju- } \\
\text { Ekiti }\end{array}$ \\
\hline 6. & 34.10 & 40.760 & 44.84652 & 45.26683 & 41.78391 & 40.66673 & 40.56538 & Oye-Ekiti 1 \\
\hline 7. & 37.80 & 41.300 & 44.97655 & 45.21302 & 41.70344 & 40.73840 & 40.35264 & Oye-Ekiti 2 \\
\hline 8. & 51.60 & 45.480 & 45.22038 & 45.41065 & 41.99782 & 40.98460 & 40.25935 & Ikole-Ekiti \\
\hline 9. & 54.20 & 54.340 & 45.25129 & 45.44641 & 42.05074 & 41.01964 & 40.72311 & $\begin{array}{l}\text { Oke- } \\
\text { Ayedun }\end{array}$ \\
\hline 10. & 57.10 & 55.460 & 45.18619 & 45.38675 & 41.96238 & 40.95143 & 40.77041 & $\begin{array}{l}\text { Odo- } \\
\text { Ayedun }\end{array}$ \\
\hline 11. & 77.10 & 47.180 & 45.40122 & 45.70471 & 42.42993 & 41.21881 & 41.06800 & Omuo-Ekiti \\
\hline
\end{tabular}

Table 6. Result of the Path Loss obtained using Ericsson, Hata-Suburban, Hata-Open, Free Space, and CCIR Path Loss Prediction Model for Route B

\begin{tabular}{|c|c|c|c|c|c|c|c|c|}
\hline $\mathrm{S} / \mathrm{N}$ & $\begin{array}{l}\text { Distant } \\
(\mathrm{Km})\end{array}$ & $\begin{array}{l}\text { Measured } \\
(\mathrm{dB})\end{array}$ & $\begin{array}{l}\text { Ericsson } \\
\text { Model } \\
\text { (dB) }\end{array}$ & $\begin{array}{l}\text { Hata- } \\
\text { Sururban } \\
\text { Model (dB) }\end{array}$ & $\begin{array}{l}\text { Hata-Open } \\
\text { Model } \\
\text { (dB) }\end{array}$ & $\begin{array}{l}\text { Free Space } \\
\text { Model (dB) }\end{array}$ & $\begin{array}{l}\text { CCIR Model } \\
\text { (dB) }\end{array}$ & Location \\
\hline 1. & 0.00 & 0.000 & 0 & 0 & 0 & 0 & 0 & Base Station \\
\hline 2. & 17.00 & 41.220 & 44.60401 & 44.40248 & 40.45927 & 40.16622 & 39.02251 & $\begin{array}{l}\text { EKSU Campus } \\
1\end{array}$ \\
\hline 3. & 17.50 & 42.400 & 44.61432 & 44.43867 & 40.51618 & 40.18765 & 38.78299 & $\begin{array}{l}\text { EKSU Campus } \\
2\end{array}$ \\
\hline 4. & 19.00 & 46.480 & 44.65544 & 44.51901 & 40.64204 & 40.24815 & 39.46451 & Central Mosque \\
\hline 5. & 37.80 & 41.300 & 44.97655 & 45.21302 & 41.70344 & 40.73840 & 40.35264 & Oye-Ekiti 2 \\
\hline 6. & 48.00 & 53.660 & 45.00726 & 45.60142 & 42.27893 & 40.90238 & 40.53898 & $\begin{array}{l}\text { Itaji } \\
\text { Community }\end{array}$ \\
\hline 7. & 52.30 & 52.920 & 45.02069 & 45.73516 & 42.47429 & 40.96053 & 40.77707 & Skye Bank \\
\hline 8. & 57.50 & 57.140 & 45.16061 & 45.64102 & 42.33691 & 41.02432 & 40.80375 & Central Mosque \\
\hline
\end{tabular}

Table 7. Results of the Path Loss obtained using Ericsson, Hata-Suburban, Hata-Open, Free Space Path Loss Prediction Model for Route C

\begin{tabular}{lllllll}
\hline S/N & Distance $(\mathrm{km})$ & Measured & Free space & Ericsson & Hata(suburban) & Hata(open) \\
\hline $\mathbf{1}$ & 17.00 & 41.22 & 40.17 & 44.740 & 44.40248 & 40.45927 \\
$\mathbf{2}$ & 17.5 & 42.40 & 40.19 & 44.747 & 44.43867 & 40.51618 \\
$\mathbf{3}$ & 19.00 & 46.48 & 40.25 & 44.788 & 44.51901 & 40.64204 \\
$\mathbf{4}$ & 25.70 & 48.50 & 40.47 & 44.767 & 45.12642 & 41.5734 \\
$\mathbf{5}$ & 34.40 & 49.10 & 40.67 & 44.723 & 45.38401 & 41.95832 \\
$\mathbf{6}$ & 38.10 & 49.90 & 40.74 & 44.856 & 45.32731 & 41.84707 \\
$\mathbf{7}$ & 39.40 & 49.90 & 40.78 & 44.887 & 45.35975 & 41.92231 \\
$\mathbf{8}$ & 43.70 & 50.50 & 40.84 & 44.861 & 45.43812 & 42.23804 \\
$\mathbf{9}$ & 45.10 & 50.60 & 40.86 & 44.980 & 45.59532 & 41.99161 \\
$\mathbf{1 0}$ & 47.80 & 51.20 & 40.9 & 44.990 & 45.44296 & 42.12199 \\
$\mathbf{1 1}$ & 52.10 & 51.60 & 40.95 & 45.086 & 45.47241 & 42.08914 \\
$\mathbf{1 2}$ & 53.00 & 51.90 & 40.97 & 44.964 & 45.73882 & 42.47962 \\
\hline
\end{tabular}




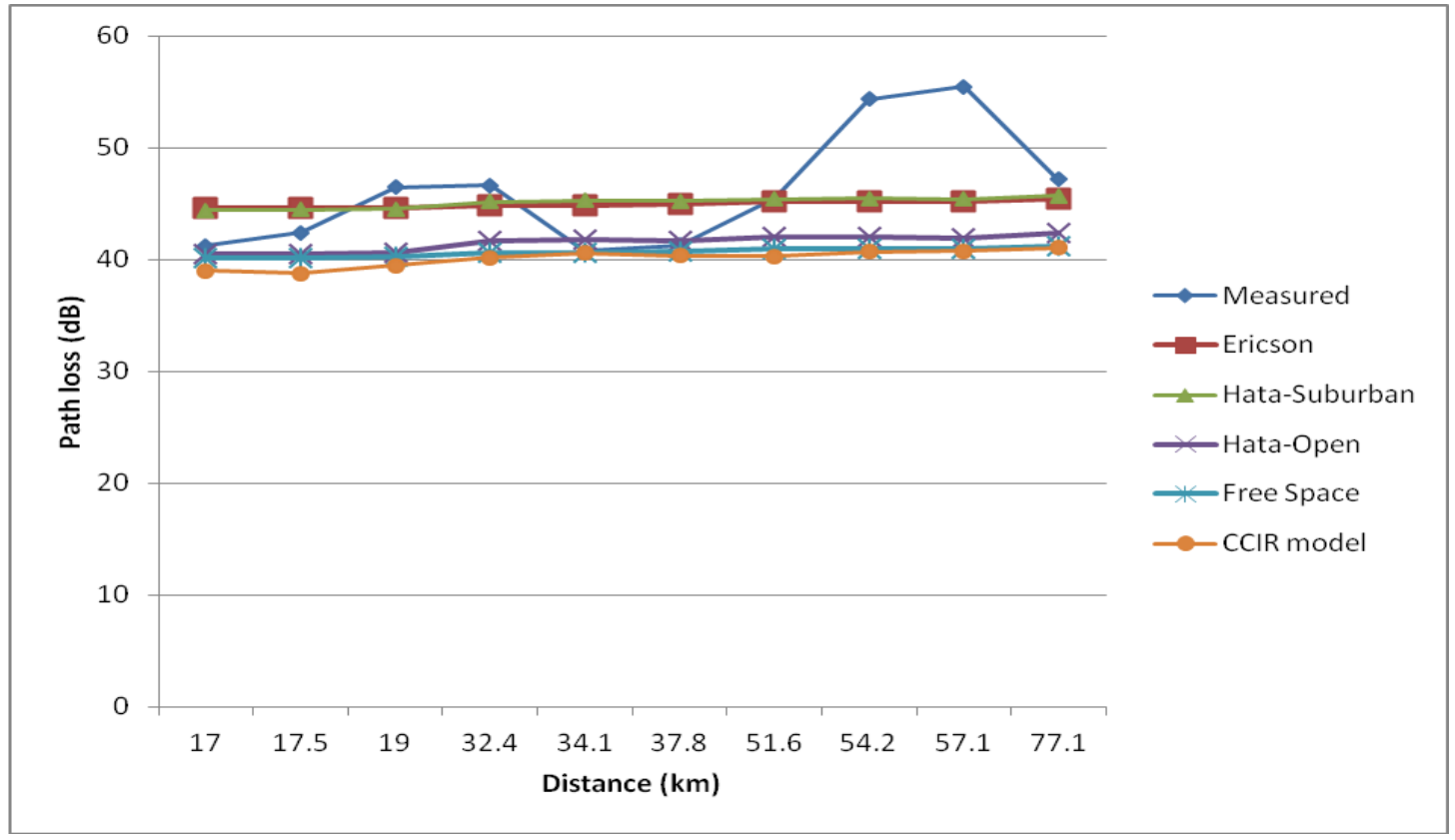

Fig.8. Comparison f Empirical and Measured Path loss for Route A

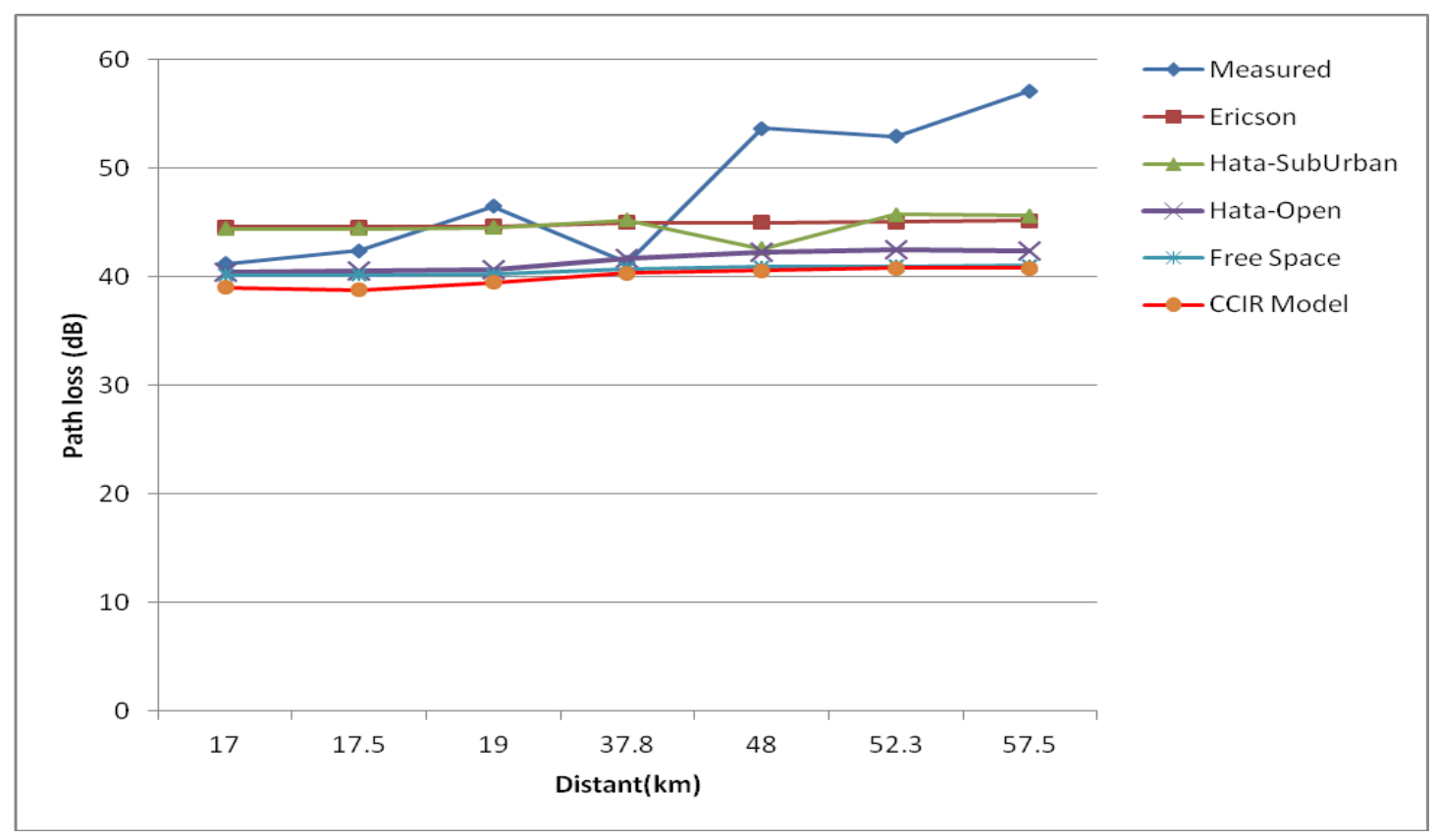

Fig.9. Comparison f Empirical and Measured Path loss for Route B 


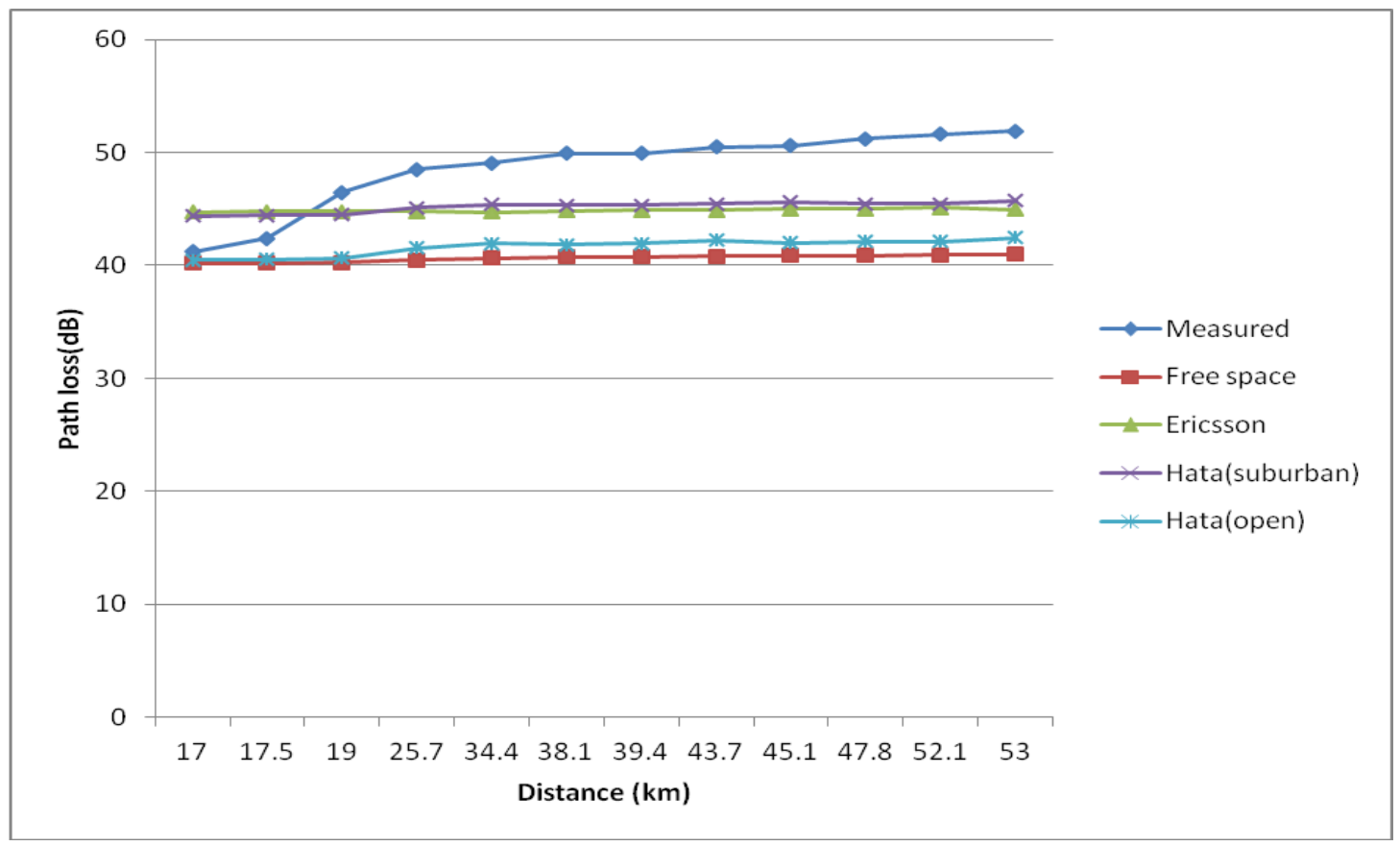

Fig.10. Comparison f Empirical and Measured Path loss for Route C

Table 8 shows the root mean square errors (RMSE) of the path loss models for the three routes considered. For route A, the RMSE is too large for all the models. The results indicate that none of the models can be uses to predict the path loss in the route. The Hata model is howver observed to have the least RSME. The large value of the RMSE can be attributed to the terrain of the route. The route is highly hilly with lot of valley along the path of measurement. For route B, it can be observed from the table that Hata model have the least RMSE with a value that is less than $6 \mathrm{~dB}$. This implies that the Hata(Sub-Urban Model) can be used to predict the path loss alonge this route. For route C, the Hata(Sub-Urban Model) is also observed to have the least RMSE. It is also observed from the table that the Ericson model also have a RMSE of less than 6dB. This implies that both the Ericson and the Hata(Sub-Urban Model) can be used to predict the path loss along this route but with the HATA model giving a better result.

Table 8. Root Mean Square Errors of the Path Loss Models

\begin{tabular}{llllllll}
\hline S/N & Routes & $\begin{array}{l}\text { Ericsson } \\
\text { Model }\end{array}$ & $\begin{array}{l}\text { Hata(Sub-Urban } \\
\text { Model) }\end{array}$ & Hata(Open- Model) & $\begin{array}{l}\text { Free } \\
\text { Model }\end{array}$ & Space & CCIR model \\
\hline $\mathbf{1 .}$ & A & 35.29061 & 34.95069 & 42.14418 & 42.96479 & 40.13408 \\
$\mathbf{2 .}$ & B & 6.296998 & 5.961859 & 8.991424 & 9.330689 & 8.069566 \\
$\mathbf{3}$ & C & 4.97000 & 4.51000 & 7.47000 & 8.56000 & 7.01 \\
\hline
\end{tabular}

\section{Conclusions}

This work focuses on the analysis of VHF propagation path loss for Ekiti State, Nigeria. The field strengths of NTA broadcasting station, Ado Ekiti were measured in some selected locations along three routes in the state. Results show that the propagation signal of the station was generally poor along the routes considered. The deviation of the measured path loss with the free space path loss exceeded $6 \mathrm{~dB}$ in most cases. It is 
therefore needful for the broadcasting station to increase their transmitting power or build a repeater stations along the routes considered if they are to serve the communities effectively. Some prediction models was also used to predict the path loss in these selected locations. The Hata (sub-urban) path loss prediction models have the lowest Root Mean Square Errors for the three routes considered and may be used to predict the signal propagation path loss for the state at this frequency.

\section{References}

[1] Oyetunji S.A: Determination of Propagation Path Loss and Contour Map for FM Radio Federal University of Technology, Akure, Nigeria. International Journal of Electronics and Communications Engineering (IOSR-JECE):4-9 Vol. 6, Issue 3 (May.-June. 2013)

[2] Fagbohun O.O: Studies on Electric Field Strength Distribution of UHF Television Signal Propagation in Ekiti-State. Nigeria. International Journal of Electronics and Communications Engineering (IOSR-JECE): 111-121 Vol. 9, Issue 2 (May.-April. 2014)

[3] George A.G, Rice P.L, Norton K.A and Barsts, A.P," "Transmission Loss Prediction for Tropic Communication Circuits Tech.

[4] CCIR Report 239-6, Propagation statistic required for broadcasting service using frequency range 301000 MHz, Recommendation and report of the ITU-R, Geneva, 1986, In Hall.M.(Ed); Ibid,256.

[5] Isabona Joseph, Konyehac. C, Chimule, Bright Isaiah Gregory Peter Radio Field Strength Propagation Data and Path Loss Calculation Method in UTMS Network, Vol. 21, 2013

[6] Longley, A. G., and G. A. Hufford (1975), Sensor path loss measurements analysis and comparison with propagation models, OT Report 75-74. Available from NTIS, Access. No. PB-247-638/AS.

[7] ITU-R Propagation over Irregular Terrain with and without Vegetation, Report 1145 Geneva (CD) 2000

[8] Mardeni, R.and Kwan, K.F: Optimization of Hata Propagation Prediction Model in Suburban Area in Malaysia, Progress in Electromagnetics Research C, Vol. 13,91-106 (2010).

[9] Femi-Jemilohun O.J and Stuart W.D: Path loss prediction models for Corridor propagation at 24GHz, Transactions in Networks and Communications, Society for Science and Education, United Kingdom, vol.2, issue4, 2014

[10] Nadir,Z; Seasonal Path Loss Modelling at 900MHz for Oman,2011 International Conference on Telecommunication Technology and Applications, Proc. of CSIT Vol. 5(2011). IACSIT Press, Singapore

[11] Milanovic, J, Rimac-Drlje and Bejuk, K; Comparison of Propagation Model Accuracy for WiMAX on 3.5GHz. $14^{\text {th }}$ IEEE International Conferenceon Electronic Circuits and Systems, Morocco, pp. 111-114 (2007)

[12] ITU-R VHF and UHF Propagation Curves for Land and Mobile Services Rec. 529, Report 567-3, Geneva (CD), 2000

[13] John S. Seybold Introduction to RF Propagation John Wiley and Sons, 2005 ISBN 0-471-655996 page 143

[14] A. Medeisis and A. Kajackas, "On The Use of the Universal Okumura-Hata Propagation Model in Rural Areas", Vehicular Technology. Conference Proceedings, VTC Tokyo, Vol.3, pp. 1815-1818, May 2000

[15] Z. Nadir, N. Elfadhil, and F. Touati Path Loss determination using Okumura-Hata Model and Spline Interpolation For Missing Data for Oman Proceedings of the world Congress on Engineering 2008 Vol. 1 WCE 2008, July 2-4,2008,London, UK

[16] A Akinbolati, O. Akinsanmi and K. R. Ekundayo: Signal strength variation and propagation profile of UHF Radio wave channel in Ondo State, Nigeria. International journal of wireless and microwave Technology (ijwmt), 2016,4,12-28.

[17] http://www.earth google /map gallery 


\section{Authors' Profiles}

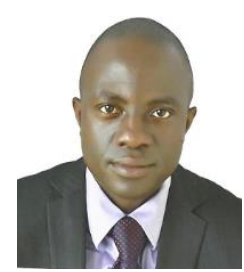

Ilesanmi B. Oluwafemi received the B.Eng degree in Electrical and Electronic Engineering from University of Ado Ekiti, Nigeria in 2000. He obtained the Master of Engineering degree in Electronic and Telecommunication from University of Benin, Nigeria in 2005 and $\mathrm{PhD}$ in Electronic Engineering from the University of KwaZulu-Natal, Durban, South Africa in 2012. He is currently a Senior Lecturer and the Head of Department of Electrical and Electronic Engineering, Ekiti State University, Nigeria. He is also the Leader of the Center for Research in Electrical Communication (CRECO), Ekiti State University, AdoEkiti, Nigeria. His research interests are in the area of wireless communication including space-time coding, channel coding, MIMO and OFDM systems and signal propagation.

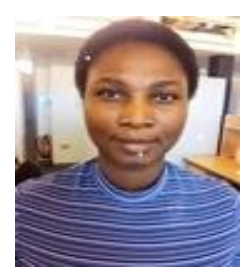

Femi-Jemilohun Oladunni J. received her B.Eng. degree in Electrical and Electronic Engineering from Ondo State University, Ado Ekiti, Nigeria in 1997 and M.Eng degree from Federal University of Technology, Akure, Ondo State, Nigeria in 2010. She obtained a $\mathrm{PhD}$ in Electronic Engineering from School of Computer Science and Electronic Engineering, University of Essex, Colchester, United Kingdom in 2015. She is currently a Lecturer at Ekiti State University, Ado Ekiti, Nigeria. Her research interests are in wireless communication including NLoS wireless propagation at Millimetre Wave Spectrum.

How to cite this paper: I. B. Oluwafemi, O. J. Femi-Jemilohun,"Propagation Profile and Signal Strength Variation of VHF Signal in Ekiti State Nigeria", International Journal of Wireless and Microwave Technologies(IJWMT), Vol.7, No.3, pp.9-24, 2017.DOI: 10.5815/ijwmt.2017.03.02 